\title{
PROJETO PAULO FREIRE DE MOBILIDADE ACADÊMICA E A FORMAÇÃO CONTINUADA DE PROFESSORES DA REDE ESTADUAL DA BAHIA
}

\author{
PROYECTO PAULO FREIRE DE MOVILIDAD ACADÉMICA \\ Y LA FORMACIÓN CONTINUADA DE PROFESORES \\ DE LA RED ESTADUAL DE BAHÍA
}

\author{
PAULO FREIRE PROJECT FOR ACADEMIC MOBILITY \\ AND CONTINUED TEACHER TRAINING OF THE BAHIA STATE
}

Gabriela Rodella de OLIVEIRA $^{1}$

RESUMO: A Universidade Federal do Sul da Bahia (UFSB), com o apoio da Organização de Estados Ibero-Americanos para a Educação, a Ciência e a Cultura (OEI), do Ministério da Educação (MEC) e da Secretaria de Educação do Estado da Bahia (SEC/BA), em atendimento a uma demanda institucional da SESu/MEC, apresentou, em outubro de 2016, uma proposta de programa-piloto de Mobilidade Acadêmica para o Projeto Paulo Freire. Tal programa, cujo objetivo principal é proporcionar aos estudantes das Licenciaturas Interdisciplinares (LI) da UFSB uma experiência formativa de mobilidade acadêmica, estendeu-se também para a formação continuada de professores da rede estadual de ensino básico da Bahia atuantes nos Complexos Integrados de Educação (CIE), que possuem convênio com a universidade. Os CIE têm como meta oferecer educação em tempo integral e constituem espaços privilegiados de prática docente para licenciandos das LI da UFSB e de formação continuada para professores da rede. Entre setembro e outubro de 2017, vinte professores dos três CIE parceiros da UFSB (CIE Itabuna, CIE Porto Seguro e CIE Itamaraju), acompanhados por uma equipe técnica da universidade, estiveram no Uruguai para uma estada acadêmica de formação continuada, marco do convênio de cooperação e intercâmbio entre a UFSB e a Administración Nacional de Educación Pública (Anep), o Consejo de Formación en Educación (CFE) e a Universidad de la República (Udelar), que se configurou como um espaço de aproximação a programas e propostas educativas do Uruguai. Sobre essa intensa experiência, buscar-se-á refletir neste relato.

PALAVRAS-CHAVE: Formação continuada de professores. Mobilidade acadêmica. Projeto Paulo Freire. Complexo integrado de educação (CIE).

RESUMEN: La Universidad Federal del Sur de Bahía (UFSB), con el apoyo de la Organización de Estados Iberoamericanos para la Educación, la Ciencia y la Cultura (OEI), del Ministerio de Educación (MEC) y de la Secretaría de Educación del Estado de Bahía (SEC/BA), en respuesta a una demanda institucional de SESU/MEC, presentó en octubre de 2016 una propuesta de programa piloto de Movilidad Académica para el

\footnotetext{
${ }^{1}$ Universidade Federal do Sul da Bahia (UFSB), Teixeira de Freitas - BA - Brasil. Professora Adjunta no Instituto de Humanidades, Artes e Ciências (IHAC). ORCID: 〈https://orcid.org/0000-0002-5822-1143>. Email: gabirodella@gmail.com
}

RIAEE - Revista Ibero-Americana de Estudos em Educação, Araraquara, v. 13. n. esp. 2, p. 1374-1387, set., 2018. ISSN: 1982-5587. 
Proyecto Paulo Freire. Este programa, cuyo objetivo principal es proporcionar a los estudiantes de las Licenciaturas Interdisciplinarias (LI) de la UFSB una experiencia formativa de movilidad académica, se extendió también para la formación continuada de profesores de la red estadual de enseñanza básica de Bahía actuantes en los Complejos Integrados de Educación (CIE), que tienen convenio con la universidad. Los CIE tienen como meta ofrecer educación integral a tiempo completo y constituyen espacios privilegiados de práctica docente para licenciandos de las LI de la UFSB y de formación continuada para profesores de la red. Entre septiembre y octubre de 2017, veinte profesores de los tres CIE asociados de la UFSB (CIE Itabuna, CIE Porto Seguro y CIE Itamaraju), acompañados por un equipo técnico de la universidad, estuvieron en Uruguay para una estancia académica de formación continuada, marco del convenio de la cooperación e del intercambio entre la UFSB y la Administración Nacional de Educación Pública (ANEP), el Consejo de Formación en Educación (CFE) y la Universidad de la República (Udelar), que se configuró como un espacio de aproximación a programas y propuestas educativas del Uruguay. Sobre esa intensa experiencia, se buscará reflexionar en esta historia.

PALABRAS CLAVE: Formación continuada de profesores. Movilidad académica. Proyecto Paulo Freire. Complejo integrado de educación (CIE).

ABSTRACT: The Federal University of Bahia (UFSB), with the support of the Organization of Ibero-American States for Education, Science and Culture (OEI), the Ministry of Education (MEC) and the Bahia State Department of Education (SEC/BA), in response to an institutional demand from SESu/MEC, presented, in October 2016, a proposal for a pilot program of Academic Mobility for the Paulo Freire Project. This program, whose main objective is to provide students of the UFSB Interdisciplinary Degree (LI) with a formative experience of academic mobility, has also been extended to the continuing training of teachers of the Bahia state primary education system working in Integrated Education Complexes (CIE), which have an agreement with the university. The CIE's aim is to provide full-time education and constitute privileged spaces for teaching practice for UFSB LI graduates and continuing education for teachers. Between September and October 2017, twenty teachers from the three CIE partners of UFSB (CIE Itabuna, CIE Porto Seguro and CIE Itamaraju), accompanied by a technical team from the university, were in Uruguay for an academic stay of cooperation and exchange between the UFSB and the National Administration of Public Education (ANEP), the Education Training Council (CFE) and the University of the Republic (Udelar), which was set up as a space for approaching educational programs from Uruguay. On this intense experience, we will briefly reflect on this report.

KEYWORDS: Continuing teacher training. Academic mobility. Paulo Freire Project. Integrated education complex (CIE).

\section{Introdução}


"A libertação através da educação é um esforço coletivo." Paulo Freire

O Projeto Paulo Freire de Mobilidade Acadêmica para Estudantes de Programas Universitários de Formação de Professores surge na XXIV Conferência Ibero-americana dos Ministros da Educação, promovida pela Organização de Estados Ibero-Americanos para a Educação e a Cultura (OEI), na Cidade do México, em agosto de 2014. Ele é proposto considerando-se os pressupostos de que a mobilidade acadêmica é um elemento fundamental no processo de internacionalização da educação superior, de que ela pode fomentar uma formação cultural, técnica, múltipla e diversificada aos graduandos que se tornarão professores da Educação Básica e de que ela se torna também uma maneira, entre outras, de enfrentarem-se os múltiplos desafios de integração da comunidade iberoamericana. Como objetivos, o Projeto visa a constituir uma rede de Instituições de Ensino Superior da Ibero-América com o intuito de valorizar social e intelectualmente a carreira docente no ensino básico, priorizando-se a educação pública em seus diferentes aspectos e dimensões e o compromisso assumido pelas universidades públicas com a formação escolar. Para tal, o Projeto propõe-se a considerar programas semelhantes ou congruentes já existentes, como o Programa Pablo Neruda e/ou Programa de Intercâmbio e Mobilidade Acadêmica (Pima), práticas de intercâmbio realizadas no Mercosul, bem como o Programa Erasmus (European Action Scheme for the Mobility of University Students), da União Europeia.

Em setembro de 2016, a diretora da OEI no Brasil, Adriana Weska, participa de Grupo de Trabalho (GT) proposto pela Universidade Federal do Sul da Bahia (UFSB) visando à proposição de um Programa-Piloto de Mobilidade Acadêmica voltado para estudantes das Licenciaturas Interdisciplinares (LI) da universidade no âmbito do Projeto Paulo Freire, em atendimento a uma demanda institucional da Secretaria do Ensino Superior (SESu/MEC). Nessa ocasião, o GT propõe uma ampliação do público-alvo do Projeto com a inclusão da participação de professores da rede estadual da Bahia atuantes nos Complexos Integrados de Educação (CIE), escolas de educação em tempo integral com as quais a universidade desenvolve parceria, a partir de um convênio firmado em 2015 com a Secretaria de Educação do Estado da Bahia (SEC). Trata-se de três unidades da rede estadual de ensino médio, cada uma delas próxima a um dos campi da UFSB, nas cidades de Itabuna, Porto Seguro e Itamaraju, que contam com assessoria pedagógica da 
universidade por meio da atuação de coordenadores de práticas pedagógicas, docentes da universidade que dedicam parte de sua carga horária ao trabalho nas escolas. Portanto, os CIE recebem apoio pedagógico, que inclui a formação continuada de professores, para que seu corpo docente planeje e participe de projetos de ensino e aprendizagem integrados e interdisciplinares, recebendo licenciandos da UFSB para estágios supervisionados de acompanhamento desses projetos e do cotidiano das escolas.

O GT define, então, com a anuência da OEI, que o Programa-Piloto da UFSB será estruturado em rede de cooperação entre instituições de ensino superior do Brasil, do Uruguai, da Colômbia e da Argentina, além de Portugal e Espanha, considerando-se as facilidades logísticas e de acesso a esses países. O Uruguai é o país parceiro escolhido para a primeira edição do Projeto, desenvolvida entre setembro de 2017 e junho de 2018, garantindo a experiência de mobilidade acadêmica por meio de estágios a 40 estudantes das LI da UFSB e a 20 professores da rede estadual da SEC-BA. São previstas, portanto, 60 bolsas de estudos para os participantes do Projeto, sendo a ida dos estudantes e professores planejada para dois momentos distintos: 1) a viagem dos 20 professores da rede acompanhados de equipe técnica da UFSB para atividades no Uruguai entre final de setembro e começo de outubro de 2017, perfazendo 15 dias; 2) a viagem dos 40 estudantes entre março e maio de 2018, ao longo de 45 dias, também acompanhados de equipe técnica da universidade.

Desde abril de 2017 na função de coordenadora de práticas pedagógicas do CIE Itamaraju, vinculado ao Campus Paulo Freire da UFSB, participei da equipe técnica que acompanhou a ida dos professores da rede ao Uruguai e das atividades do Projeto Paulo Freire desenvolvidas no país. É sobre a experiência de formação continuada em serviço vivida por esses professores, propiciada pela parceria entre UFSB, SEC/BA e OEA, que este artigo pretende refletir, buscando compreender os processos de transformação do conhecimento e da construção das subjetividades e das identidades a partir do contato com outra cultura e com práticas docentes semelhantes e diversas. A reflexão a que me proponho aqui será realizada a partir de minha própria experiência, da observação participante dos professores ao longo da viagem e da análise dos relatórios por eles elaborados como produto final do estágio de mobilidade no retorno ao Brasil.

\section{Processo de seleção e preparação para a viagem}


O processo seletivo dos professores dos CIE que participaram da primeira etapa de estágio de mobilidade acadêmica do Projeto Paulo Freire deu-se por meio de edital publicado no site da universidade. Das 20 vagas previstas para professores da rede estadual baiana, seis bolsas foram destinadas ao CIE Itabuna, seis ao CIE Porto Seguro, seis ao CIE Itamaraju (CIEI) e as duas últimas foram distribuídas entre os CIE com maior número de inscrições. Para participar, além dos documentos exigidos e do preenchimento de um formulário, os professores candidatos se submeteram a critérios de classificação que consideraram: a) sua atuação como professores supervisores recebendo estagiários da UFSB em suas aulas; b) suas cartas de intenção, produzidas em forma de memorial docente para a participação no edital; c) suas eventuais atuações como articuladores pedagógicos nas escolas.

Como parte da equipe técnica da UFSB no Projeto, orientei o processo de produção das cartas de intenção dos professores do CIEI e participei do processo de seleção dos professores dos outros dois complexos. A princípio, a proposta da seleção era a produção de textos simples em que os professores explicavam os motivos que os levavam a querer participar do Projeto e a viajar para o Uruguai para conhecer a realidade pedagógica do país vizinho. As cartas dos professores da escola transformaram-se em memoriais, nos quais os candidatos refletiram sobre a formação da escola, sobre a proposta de trabalho com novas metodologias e com projetos de trabalho, sobre a perspectiva interdisciplinar trazida pela universidade a partir do convênio estabelecido e sobre os problemas, as dificuldades e as surpresas encontrados ao longo do caminho de reorganização da escola.

O CIEI foi o complexo que maiores obstáculos enfrentou em sua transformação em escola de educação em tempo integral, pois sua criação surgiu com a fusão de três escolas de ensino médio de Itamaraju, em janeiro de 2016. A aglutinação de três corpos docentes gerou insegurança e desconforto, e teve como consequência a reorganização de funções e posições de modo traumático. Além disso, as condições de infraestrutura para o atendimento básico dos pressupostos que uma escola em tempo integral deve seguir não foram atendidas nesse primeiro momento. A situação culminou em uma profunda resistência da gestão à frente da escola, na época, ao projeto e ao apoio pedagógico da universidade, o que levou a equipe pedagógica da universidade a optar, então, pela suspensão do vínculo, até que medidas de práticas emergenciais fossem tomadas pela SEC. Depois de um afastamento que durou de agosto de 2016 a março de 2017, houve uma reaproximação entre CIEI e UFSB, em atendimento a uma demanda da atual gestão e de 
parte do corpo docente da escola. A reflexão sobre todo esse percurso do convênio está presente nas cartas escritas pelos professores para a seleção do Projeto Paulo Freire, como fica claro nos excertos a seguir:

[...] fazia parte do quadro funcional de uma das escolas dissolvidas em função da implantação do CIE de Itamaraju, e, desde então, sou docente na área de Ciências Humanas. Romper com tudo que tínhamos construído nas escolas que trabalhávamos, nos reunindo e recomeçando em uma única escola, não foi uma circunstância tranquila. Foi um impacto e o caos. Entretanto, aprendi que esse fenômeno, aparentemente assustador, é antagônico. Pois, ao passo que imprimiu medo e tristeza, buliu as estruturas mais cristalizadas, transformando atitudes e convicções, até então imóveis. [...] Trabalhar à luz da proposta pedagógica da UFSB tem possibilitado este exercício e rever práticas escolares engessadas em grades curriculares, que sempre nos mantiveram distantes e indiferentes ao mundo que se move continuamente em círculos sempre mais amplos. [...] A aspiração de participar do programa de mobilidade acadêmica Paulo Freire, portanto, representa mais uma oportunidade de alargamento dessas perspectivas, ou seja, levar em conta o papel que as relações individuais e coletivas exercem em diferentes modos de pensar o cotidiano; a casa, o território, as identidades, o meio ambiente, entre tantos outros saberes, para além das fronteiras de um currículo único (JARDIM, 2017a, s/p).

Depois de tantos conflitos e insatisfações, a UFSB anuncia retirada [em agosto de 2016] para que a SEC regularizasse o caos que no momento era mais de ordem estrutural do que pedagógica; não que o pedagógico não tivesse problemas, mas no momento era irrelevante frente à muralha construída entre professores, direção e SEC. [...] Agora em 2017 começamos o ano letivo sem a participação da UFSB, mas seguindo orientações do Núcleo Territorial de Educação 7. Realizamos a nossa jornada pedagógica juntamente com uma roda de discussões acerca das propostas para trabalhar em 2017 e uma delas foi solicitar a retomada da UFSB. Acredito que depois dessa desconstrução e construção estamos preparados para o fazer coletivo [...]. Em vista dos questionamentos que ainda estão "inquietos, impacientes, continuados e esperançosos" que ainda continuam vivos dentro de mim é que surgiu o meu interesse pelo Programa de Mobilidade Acadêmica Paulo Freire com bolsa para o Uruguai. O meu interesse consiste na possibilidade de aprimorar/ampliar os conhecimentos adquiridos na instituição de ensino no qual trabalho como articuladora pedagógica [...]. Dessa forma, pretendo alcançar novos olhares, com novas perspectivas de excelência na minha área de atuação; permitindo vislumbrar impactos positivos na construção de uma educação multidisciplinar e incentivadora aos alunos do CIEI (SANTOS, 2017, $\mathrm{s} / \mathrm{p})$.

Constata-se, portanto, a importância simbólica do intercâmbio proposto pelo Projeto Paulo Freire no que tange ao fortalecimento do vínculo de confiança entre universidade e escola, tecendo relações entre o que a universidade pode oferecer como 
formação continuada e o que os professores podem desenvolver como metodologias inovadoras em suas salas de aula.

Como preparação para o estágio dos docentes da rede no país receptor nesse primeiro projeto-piloto, foi realizada a 1. ${ }^{a}$ Roda de Conversa Formativa, com a presença dos professores da rede selecionados para participarem do Projeto e dos docentes e técnicos da universidade membros da equipe técnica da UFSB. O encontro ocorreu no Campus Jorge Amado da UFSB, em Itabuna, ao longo de dois dias de trabalho intenso, e incluiu:

1) Roda de conversa formativa sobre o círculo de cultura freireano, conduzida pela Profa. Dra. Rosemary Aparecida Santiago (UFSB/CJA);

2) Encontro presencial do curso de língua espanhola para o grupo de mobilidade acadêmica;

3) Oficina de construção dos planos de trabalho dos docentes da SEC-BA para o Projeto Paulo Freire com as coordenadoras pedagógicas dos três CIE-UFSB;

4) Videoconferência com a equipe do Uruguai (composta por representantes da Administración Nacional de Educación Pública - Anep e da Universidad de la República del Uruguay - Udelar);

5) Encerramento com oficina de formação Pedagogia do bem-querer, com o Prof. Me. Erashto Felício (IFBA/Valença).

No encontro, os professores das três escolas puderam se conhecer pessoalmente e construíram consensos acerca das expectativas com relação à viagem, levantaram possibilidades de desenvolvimento de planos de trabalho compartilhados, além de terem constituído uma identidade como grupo que partiria ao Uruguai para uma estada pedagógica em poucos dias. Vale ressaltar aqui que para muitos dos professores da rede estadual da Bahia essa foi a primeira viagem ao exterior, e esse momento serviu também para que angústias e ansiedades relativas a essa questão pudessem ser expostas e trabalhadas no grupo.

\section{Atividades no Uruguai}


No Uruguai, desenvolveram-se diversas atividades de imersão na educação e na cultura do país vizinho, em uma agenda especialmente elaborada pela equipe uruguaia. Tais atividades tiveram início com as boas-vindas à comitiva brasileira pelas autoridades do Centro de Formação em Educação do Uruguai (CFE) e por docentes da Udelar, e foram seguidas por uma série de conferências, visitas a escolas e participação em eventos abertos ao público de professores em geral. Na sequência, registro as atividades desenvolvidas, pois por meio delas foi possível entrar em contato com diversos aspectos da educação básica uruguaia e da formação docente no país vizinho. Em todos os momentos, a interação com nossos professores da rede estadual foi promovida e, apesar de falarmos línguas diferentes, a comunicação fluiu bem.

Entre as conferências organizadas especificamente para o grupo de professores brasileiros constam: "Sistema Nacional de Educação no Uruguai, Institucionalidade da Formação Docente no Uruguai”, proferida pelo Prof. Dr. Gustavo Klein, no Instituto de Perfeccionamiento y Estudios Superiores (IPES); "Análise da realidade nacional de uma perspectiva geopolítica" e "A didática na formação docente uruguaia”, pelo Prof. Fernando Pesce (IPES); "Interdisciplinaridade em cognição para o ensino e a aprendizagem", apresentada por representantes pesquisadores da Equipe do Centro Interdisciplinario en Cognición para la Enseñanza y el Aprendizaje (Cicea); “A interdisciplinaridade como espaço de ensino, investigação e extensão”, a cargo da PhD Ana María Corbacho (Udelar); "Os desafios da formação docente no Uruguai”, proferida pela Profa. Lic. Me. Dinorah Motta de Souza; "Aspectos relevantes sobre a educação de adultos", a cargo do Prof. Dr. Aldo Rodrígues, do Liceo n. ${ }^{\circ}$ 34; "Projetos de Ceibal destinados a alunos e docentes do ensino primário e médio", por Lic. Alejandra Otero, no Ceibal; "Informe sobre a situação atual da educação no Uruguai”, proferida pelos professores Dra. Carmen Haretche e Me. Federico Rodríguez, do Instituto Nacional de Evaluación Educativa (Ineed). E, a convite, a delegação brasileira expôs peculiaridades de nossa educação por meio da conferência: “A formação docente no Brasil no Estado da Bahia".

As visitas a escolas em Montevidéu ou próximas à capital, em que a equipe pôde assistir às aulas e conversar com estudantes e professores, foram: "Classe aberta de Expressão Corporal e Teatro", com a docente Stella Rovena, sob responsabilidade da Profa. Mariella Chiossoni, no Liceo n. ${ }^{o}$ 35, Instituto Alfredo Vásquez Acevedo (Iava); "Classe aberta de Expressão Corporal e Dança”, com a docente Vera Garat, também sob responsabilidade da Profa. Mariella Chiossoni, no Liceo Iava; "Experiência educativa: 
Grupo de Teatro Trampantojo", com os docentes Ariel Eguren e Christián Pomiés; Biblioteca Central Secundária e Museu de História Natural, do Liceo Iava; conversa com estudantes sobre "Experiência educativa: robótica e leptospirose", no Liceo de Tala; e visita acadêmica à Escuela de Jaureguiberry, “Uma escola autossustentável”.

Além disso, a comitiva brasileira participou do Congreso Uruguai Experience, atendendo às conferências 'Detecção precoce de perfis não neurotípicos: do 'Fracasso' ao 'Caso' escolar", por Dra. Victoria Poenitz, e "Neurociência aplicada à educação: construindo a ponte (O que serve e o que não serve na educação?)", por Dr. Fabián Román; da V Jornada de Pedagogia Audiovisual, vinculada ao Programa Cineduca, cuja conferência central foi proferida pelo Prof. Dr. Cezar Migliorin, da Universidade Federal Fluminense (UFF), com quem a UFSB desenvolveu projeto conjunto de oficinas de vídeo voltadas para os estudantes das escolas; e das Jornadas acadêmicas sobre inovação e investigação (Ipes), na qual falaram professores uruguaios do CFE e professores brasileiros dos CIE.

Dentre a diversidade de atividades propostas citadas, destaco a seguir aquelas que mais tiveram impacto sobre a comitiva de professoras de Itamaraju, a partir da leitura de seus relatórios, documentos cuja elaboração estava prevista no Projeto.

A primeira conferência, proferida por Gustavo Klein, professor de Física e doutor em Educação, foi citada nos relatórios não apenas porque expôs dados relativos ao sistema de Educação do Uruguai, imprescindíveis para que as visitas às escolas tivessem embasamento e para que as trocas entre professores brasileiros e uruguaios pudessem ir além de um mero reconhecimento, mas também porque apresentou como se processa a formação dos docentes no país. Como pode ser lido nos relatórios, a Lei n. ${ }^{\circ}$ 18.437/2008 estabelece a educação no Uruguai como um direito humano, bem público, que deve ser inclusiva e embasada nos princípios da justiça, solidariedade, autonomia e do desenvolvimento integral, além de prezar pela gratuidade, laicidade, igualdade de oportunidade e equidade. Sendo organizado em quatro níveis - a saber: educação préescolar, educação primária, educação média: ciclo básico e bacharelado, e educação terciária ou superior -, o ensino é garantido para todos, pois o sistema disponibiliza vagas a quem queira estudar. Contudo, além da garantia da vaga, o Estado não disponibiliza nenhum apoio extra, ficando todo o restante relativo à educação a cargo das famílias de origem dos estudantes, o que leva a altos níveis de evasão nos dois últimos ciclos. A diferença em relação ao que vivenciam os professores no Brasil, quanto ao envio de 
merenda garantido pela SEC ou à distribuição de livros didáticos pelo Fundo Nacional de Desenvolvimento da Educação (FNDE), por exemplo, foi observada nos relatórios:

O Ministério da Educação - MEC Uruguai, ao contrário do Brasil, não oferece merenda escolar e nem fornece o livro didático para as escolas. Cada instituto junto com os pais dos alunos tem autonomia para escolher o seu material didático, e os alunos levam o seu próprio lanche (LADEIA, 2017, p. 13).

Uma realidade que nos chamou bastante a atenção foi em relação às políticas públicas suplementares para a escola e o estudante. Não existe programa de financiamento para planos ou projetos na escola, não há repasses de recursos direto às escolas. As políticas voltadas aos estudantes são praticamente inexistentes, a única que nos foi apresentada foi o plano Ceibal (SANTANA, 2017, p. 22).

Corroborando a fala de Gustavo Klein, a conferência assistida pela delegação brasileira no Ineed, cuja função é semelhante ao Instituto Nacional de Estudos e Pesquisas Anísio Teixeira (Inep) no Brasil, apresentou dados relativos ao último censo educacional uruguaio, ocorrido em 2015. Chamou a atenção das professoras do CIEI o fato de $68 \%$ das crianças de 3 anos estarem na escola, bem como $91 \%$ das de 4 anos, 99\% das de 5 anos, 86\% dos jovens de 15 anos, $78 \%$ dos de 16 anos e $72 \%$ dos de 17 anos, destacando-se que os níveis de alfabetização propalados são próximos dos $100 \%$ da população. Contudo, nos relatórios também estão presentes os dados relativos ao número de adolescentes atrasados em seus estudos: 29\% dos de 13 anos e 39\% dos de 17 anos (INEEd, 2017, p. 8-10). Além disso, para as professoras, um dos dados mais impressionantes é o que trata dos estudantes que têm sucesso em finalizar seus estudos no ensino superior aos 21 anos, idade considerada a ideal: apenas 6 a cada 100 estudantes (INEEd, 2017, p.15). Sobre essas questões, uma das professoras afirma:

Outra diferença em relação ao nosso sistema de ensino é a forma de acesso ao ensino superior, que "aparentemente" é livre, aberta, sem barreiras com exames classificatórios. Todos os que conseguem chegar ao final do ensino médio têm sua vaga garantida na universidade, inclusive nos cursos de grande prestígio e procura aqui no Brasil. A dificuldade enfrentada pelos jovens é permanecer até o final do curso (SANTANA, 2017, p. 22).

Ponto alto das atividades desenvolvidas no Uruguai foi também a conferência do Prof. Dr. Fernando Pesce sobre a realidade do Uruguai de um ponto de vista geopolítico. Planejada para que um panorama histórico da formação do país pudesse ser conhecido pela 
delegação brasileira, a palestra transformou-se em momento de discussão acerca de questões "não oficiais", em função da abertura para questões dos professores, que tratavam das origens étnicas do país. Discorrendo sobre o massacre dos líderes indígenas ocorrido em 1830, Pesce explicou sobre as dificuldades de se resgatar uma cultura indígena que foi dizimada, enterrada e esquecida. Respondendo às questões propostas, explicou ainda sobre a fraca presença da cultura afrodescendente no Uruguai - excetuando-se a permanência do ritmo do candombe -, causada por uma economia desde sempre marcada pela pecuária e, portanto, independente da mão de obra escrava. Sobre a palestra, afirma a professora:

$\mathrm{Na}$ minha perspectiva, essa foi a atividade que mais surpreendeu, diante da exposição de questões não tão oficiais da história do Uruguai. Em uma palestra brilhante, o professor Fernando nos revelou o seu país com todos os desafios, acertos e mazelas produzidas ao longo da história (SANTANA, 2017, p. 22).

Além das atividades já citadas, a visita ao Liceo n. ${ }^{\circ} 34$ para a conversa sobre educação de adultos, preparada em atendimento a uma demanda dos professores brasileiros, talvez tenha sido também uma das mais marcantes. Organizada a partir de uma apresentação do coordenador da escola e, na sequência, por meio de roda de conversa com os professores uruguaios que participam de um projeto inovador de trabalho com educação de adultos em forma de projetos, a visita gerou reflexões e ideias para a organização do currículo dos cursos de EJA oferecidos pelos CIE e foi assunto de conversas ao longo dos dias seguintes. E as aulas que puderam ser presenciadas e observadas, de teatro, de dança e de música, fizeram parte de discussões acaloradas entre os professores de artes e de língua e literatura, bastante impressionados com o nível de exigência das professoras-artistas, já que eram efetivamente atriz, atores, bailarina e musicista.

Entre todas as diferenças observadas ao longo da estada acadêmica no Uruguai, inevitavelmente marcada pela comparação com a realidade brasileira, a questão do livre acesso à rede de computadores em qualquer espaço público uruguaio e o fato de que todos os estudantes recebem um computador portátil para acesso à rede, a materiais didáticos digitais diversos e a atividades desenvolvidas pelo plano Ceibal, foram também bastante comentados. Em uma escola cuja banda não consegue servir nem à gestão para que ela tenha acesso ao sistema da SEC, as possibilidades de trabalho pedagógico que se abrem a partir dessa proposta uruguaia chegam a parecer ficção. Entretanto, a visita ao escritório do Ceibal e a assistência a uma das aulas abertas em rede para turmas de distintas escolas de 
ensino básico sincronicamente demonstraram aos professores como um projeto como esse pode efetivamente ser colocado em prática.

\section{Considerações finais}

\section{"Al fin y al cabo, somos lo que hacemos para cambiar lo que somos."} Eduardo Galeano

Em texto intitulado "Tornar-se quem se é: educação como formação, educação como transformação", Rocha (2006) aponta uma série de pressupostos filosóficos que caracterizam a concepção tradicional de educação, por meio da discussão do pensamento da imanência. A hipótese defendida pela autora é a de que o pensamento da imanência contrapõe-se à ideia metafísica de formação (investigação das realidades que transcendem a experiência sensível e a "condução a um sujeito constituído"), à noção, antimetafísica por excelência, de transformação ou de devir (que teria relação a um "destituir-se de toda 'subjetividade"'). Nesse sentido, o que se sabe é precisamente o que deveria ser problematizado; a transformação deveria ser contínua; e aprender não deveria ser adquirir novas habilidades, acrescentar novos saberes ou conteúdos ou constituir um eu ou uma subjetividade, mas, antes, deixar de ser quem se é e reinventar-se como aquele que fala uma nova língua ou que aprende a nadar... Como afirma a autora:

Tornar-se aquele que se é não equivale a manifestar uma essência, atualizar uma potência (o que conduziria a um sujeito uno e idêntico) mas ser, a cada momento, aquele que nos tornamos; se a formação conduz à identidade, [a transformação] abre-se para a diferenciação (ROCHA, 2006, p. 278).

Mais do que uma formação continuada em serviço, creio que o Projeto Paulo Freire de Mobilidade Acadêmica representa, na verdade, uma possibilidade de transformação contínua, em que os professores podem abrir-se para o imprevisto e o devir, para a alteridade e o outro. Inúmeras foram as observações que marcaram a percepção da diferença nos relatórios recebidos ao final da viagem. No entanto, muitas foram também as observações que destacaram semelhanças e refletiram sobre o caráter do que seria uma educação mais igualitária, voltada à consolidação de sujeitos talvez mais livres para escolhas diversas e inovações. Contudo, nessa abertura à alteridade, proposta primeira do 
Projeto Paulo Freire, os professores puderam também identificar-se com o outro, princípio fundamental para a compreensão e a solidariedade:

Não muito diferente do que acontece em nosso país, alguns aspectos da educação uruguaia apresentam-se com caráter conservador. Não obstante, isto não exclui a riqueza de práticas sociais e culturais de professores, alunos e outros profissionais, bem além dos limites do currículo e das fronteiras institucionais. Identifiquei nos uruguaios que tive a oportunidade de conhecer sonhos e ideais bem comuns aos nossos; luta pela consolidação da igualdade social, educação de qualidade, valorização do profissional da educação e outros (JARDIM, 2017b, p. 2).

AGRADECIMENTOS: Agradeço às professoras do CIEI com as quais compartilhei essa estada de mobilidade acadêmica dentro do Projeto Paulo Freire pela generosidade em me autorizar a citar excertos de suas cartas de intenção e de seus relatórios finais; agradeço à OEI e à SEC-BA pela possibilidade de inserção de professores do ensino básico da rede estadual da Bahia neste projeto-piloto.

\section{REFERÊNCIAS}

INEEd. Informe sobre el estado de la educación en Uruguay 2015-2016. Síntesis y desafios. Montevideo: Ineed, 2017. 39 p.

JARDIM, L. R. Carta de intenção. Itamaraju: UFSB, ago. 2017a. [s.p.].

INEEd. Relatório para a Pró-Reitoria de Gestão Acadêmica - Programa de Mobilidade Acadêmica Internacional - Projeto Paulo Freire. Itamaraju: UFSB, out. 2017b. 3 p.

LADEIA, D. O. Relatório do intercâmbio Brasil/Uruguai "Projeto Paulo Freire de Mobilidade Acadêmica para a Formação Docente". Itamaraju/BA: UFSB, out. 2017. 51 p.

SANTANA, M. L. S. Programa de Mobilidade Acadêmica Paulo Freire: uma "mirada" sobre o sistema de ensino do Uruguai. Itamaraju: UFSB, out. 2017. 23 p.

SANTOS, E. L. Carta de intenções. Itamaraju: UFSB, ago. 2017. [s.p].

ROCHA, S. P. V. Tornar-se quem se é: educação como formação, educação como transformação. In: MARTINS, A. M. M. et al. Nietzsche e os gregos: arte, memória e educação. Rio de Janeiro: DP\&A; FAPERJ; Brasília: Capes, 2006. p. 267-278. 


\section{Como referenciar este artigo}

OLIVEIRA, Gabriela Rodella de. Projeto Paulo Freire de Mobilidade Acadêmica e a formação continuada de professores da rede estadual da Bahia. Revista Ibero-Americana de Estudos em Educação, Araraquara, v. 13. n. esp. 2, p. 1374-1387, set., 2018. ISSN: 1982-5587. DOI: 10.21723/riaee.v13.nesp2.set2018.11649

Submetido em: $12 / 03 / 2018$

Aprovado em: 03/06/2018 